\title{
Effect of Light Environment on Growth and Phenylpropanoids of Yarrow (Achillea collina cv. SPAK) Grown in the Alps
}

\author{
Annamaria Giorgi ${ }^{\mathbf{1}, 2}$, Alessandra Manzo ${ }^{1}$, Ilda Vagge ${ }^{2}$ and Sara Panseri ${ }^{1,3}$ \\ ${ }^{1}$ Centre for Applied Studies in the Sustainable Management and Protection of the Mountain Environment - Ge.S.Di.Mont., \\ Università degli Studi di Milano, Brescia, Italy \\ ${ }^{2}$ Department of Agricultural and Environmental Sciences - Production, Landscape, Agroenergy, Università degli Studi di \\ Milano, Milan, Italy \\ ${ }^{3}$ Department of Veterinary Science and Public Health, Università degli Studi di Milano, Milan, Italy \\ Received 26 May 2013, accepted 26 July 2013, DOI: 10.1111/php.12150
}

\begin{abstract}
A 2-year field study on the effect of different light environments, obtained by using cladding materials (polyethylene films and shade net) able to cut off specific regions of the photosynthetically active radiation and ultraviolet wavebands, on the growth and phenylpropanoids content of Achillea collina grown in the Alps was conducted. Overall the plant growth was strongly enhanced in the second growing season irrespective of radiation treatment. The light environment did not affect total biomass accumulation, but only carbon allocation to leaves or inflorescences. Indeed the phenylpropanoid levels in inflorescences appeared to be more sensitive to the light environment than leaves as the latter showed high constitutive amounts of these compounds. However, the use of polyethylene films improved to some extent the content of caffeic acid derivatives in leaves. Our results showed that yarrow production, in the alpine situation considered, is influenced by the growing season and the light environment, providing a basis to optimize its quality, depending on the concentration of bioactive compounds, by means of proper agronomic practices.
\end{abstract}

\section{INTRODUCTION}

Phenylpropanoids are secondary metabolite involved in the plant/ environment interactions, particularly in stress responses. They can act as chemical deterrents to herbivores and pathogens, as screening agents against harmful ultraviolet (UV) radiation and as potential scavengers of free radicals and other oxidative species (1-3). The effect of excess solar radiation and UV on the plant growth, photosynthesis and phenylpropanoids metabolism has been intensively studied $(4-11)$. An enhancement of the biosynthesis and accumulation of leaf flavonoids, especially in the epidermal layers, has been frequently observed in several plant species exposed to high irradiance and UV as they can screen out short solar wavelengths avoiding damage to the photosynthetic apparatus $(3,4,7,11)$. In addition, flavonoids, especially those with orthodihydroxilated B-ring substitution, such as quercitin 3-O and luteolin 7-O-glycosides, may efficiently dissipate excess energy and scavenge reactive oxygen species

\footnotetext{
*Corresponding author email: anna.giorgi@unimi.it (Annamaria Giorgi)
}

(c) 2013 The American Society of Photobiology
(10-12). In response to high solar radiation, a considerable role may also be played by hydroxycinnamates such as caffeic acid derivatives $(3,5)$. In several field studies, increased level of chlorogenic acid and dicaffeoyl acid due to exposition to excess solar radiation and UV has been reported $(8,9)$. In controlled environment experiment, Arabidopsis mutants lacking hydroxycinnamates sunscreen exhibited enhanced UV and oxidative damage (13). Differential induction of flavonoids or hydroxycinnamates biosynthesis be ascribed to different plant species and/or experimental conditions. Kriziek (14) has underlined that the imbalance between the UV and photosynthetically active radiation irradiation levels, usually found in controlled environment experiments, may induce misinterpretation of the results. Therefore, it appears that field studies are preferable over those conducted in controlled environment because of more realistic environmental conditions.

Modification in the amount of PAR, UV and NIR (near infrared radiation) reaching the plants by using polyethylene films or other cladding materials (e.g. shade net) is a widely used system of cultivation of horticultural and ornamental plants, by means of which it is possible to maximize or control plant growth and architecture. For instance, the use of plastic films with low transmission of far-red light has been effective in reducing plant height for the production of high-quality compact Impatiens and Petunia plants (15).

Also, UV-blocking plastic film offers an alternative way of controlling pests (16). In "Lollo Rosso" lettuce, the use of plastic films with increasing transmittance of UV wavebands induced a greater accumulation of total flavonoids and phenolics, but reduced leaf biomass and number of leaves (17). The trade-off between synthesis of primary and secondary compounds in response to high light exposure has been proposed to explain plant growth reduction occurring concomitantly with an upregulation of the production of UV-B absorbing phenolic compounds (18). In fact, as the "growth-differentiation balance theory" hypothesize, plants allocate internal resources to fulfill essential, sometimes conflicting, demands such as defense or growth (19).

As a matter of fact, a thorough evaluation of the effect of light environment would be useful in the development of strategies to increase the level of bioactive phytonutrients and, at the same time, to maintain an adequate biomass production, particularly for those crops whose quality depends on the concentration of bioactive compounds, such as herb productions (20). Also, 
this is of major relevance in mountain areas where small farmers are looking for alternative and high-value crops.

Achillea collina (Becker ex Rchb., yarrow) is a widely used herb, belonging to the Asteraceae family that grows wild and is also cultivated in the Alps (21). In previous investigations (22-24), it has been shown that yarrow is an interesting source of caffeic acid derivatives such as chlorogenic acid (CGA, 5-O-caffeoylquinic acids), di- $O$-caffeoylquinic acids (diCQA, 3,5 and 4,5 isomers) and flavonoids. These compounds possess a variety of biological activities and properties, such as antioxidant, anti-inflammatory, antibacterial, antiviral, anti-HIV, antimutagenic, anticarcinogenic, hepatocyte protective, hypocholesterolemic effects $(25,26)$. Recently, hydroxycinnamic acid lactones have been shown to possess hypoglycemic activity (27). In this study, we evaluate the long-term effect of different cladding materials, able to cut off specific PAR, UV and IR wavebands, on the growth and secondary metabolite content of yarrow cultivated in the Alps.

\section{MATERIALS AND METHODS}

Experimental conditions and growth measurements. An experimental field located in Valtellina (Italian Alps) was established in Bormio at $1050 \mathrm{~m}$ a.s.l. Two-month-old yarrow plants [A. collina (Becker ex Rchb.) cv. "SPAK"] provided by Valplantons Bio (Saillon, Switzerland), were transplanted in soil in June 2005 and mulched by polypropylene film (Retes, Milan, Italy). Plants were spaced at $30-\mathrm{cm}$ intervals in rows $40 \mathrm{~cm}$ apart, resulting in a plant density of 6.5 plants $\mathrm{m}^{-2}$. The experimental field was divided into blocks of $9 \mathrm{~m}^{2}$.

Experiments on the effect of the light environment were conducted in 2006 and 2007 using small tunnels (MS3, AGRIMEC, Casazza, BG, Italy), made of galvanized welded pipe steel $(\varnothing 28 \mathrm{~mm})$, and measuring $3 \mathrm{~m} \times 3 \mathrm{~m} \times 2.1 \mathrm{~m}(\mathrm{~W} \times \mathrm{L} \times \mathrm{H})$ on which different cladding materials were attached with metal clips. At the beginning of spring 2006, yarrow plants were covered by two polyethylene films named Clarixblue and Patilite (Idromeccanica Lucchini, Guidizzolo, MN, Italy) and by a shade net that reduces solar radiation by $70 \%$ (Retificio Padano, Ospitaletto, BS, Italy). To allow air circulation and to prevent excessive temperature increase inside the tunnels covered by polyethylene films, relatively large apertures were made on both tunnel sides. Yarrow plants were watered using an automatic watering system setting on the basis of soil humidity. Control plants were grown without any covering material (full sun). For each light treatment, three blocks (replicates) were randomly allocated in the experimental field.

The optical properties of the films used in this study, which were provided by the manufacturers, are summarized in Table 1 .

In addition, the spectral transmission between 320 and $1100 \mathrm{~nm}$ of each cladding material was assessed with a Spectroradiometer (FieldSpec HH Pro; Analytical Spectral Devices, Boulder, CO) as shown in Fig. 1.

Climatic data were collected in uncovered plot (total solar radiation, temperature and rainfall; Table 2) and were provided by Regional Agency for Environmental Protection (ARPA).

Leaf and inflorescence samples were collected in 2006 and 2007 when at least $80 \%$ of plants were in full bloom (July-August). Ten plants per block for each treatment were cut at about $20 \mathrm{~cm}$ above the soil surface and the leaves and inflorescences of 20 flowering stems were pooled and weighed immediately. For the determination of dry weight, leaves and inflorescences were then dried at $35^{\circ} \mathrm{C}$ until weight was constant.

Table 1. Summary of the optical properties of each cladding materials provided by the manufacturer.

\begin{tabular}{lccc}
\hline & $\begin{array}{c}\text { PAR } \\
(400-700 \mathrm{~nm}) \\
\% \text { transmission }\end{array}$ & $\begin{array}{c}\text { UV } \\
\text { \% transmission }\end{array}$ & $\begin{array}{c}\text { IR } \\
\text { \% retention }\end{array}$ \\
\hline Patilite & 80 & 7 & 90 \\
Clarixblue & 82 & 8 & 73 \\
Shade net & 30 & - & - $^{*}$ \\
\hline
\end{tabular}

*Data not available.

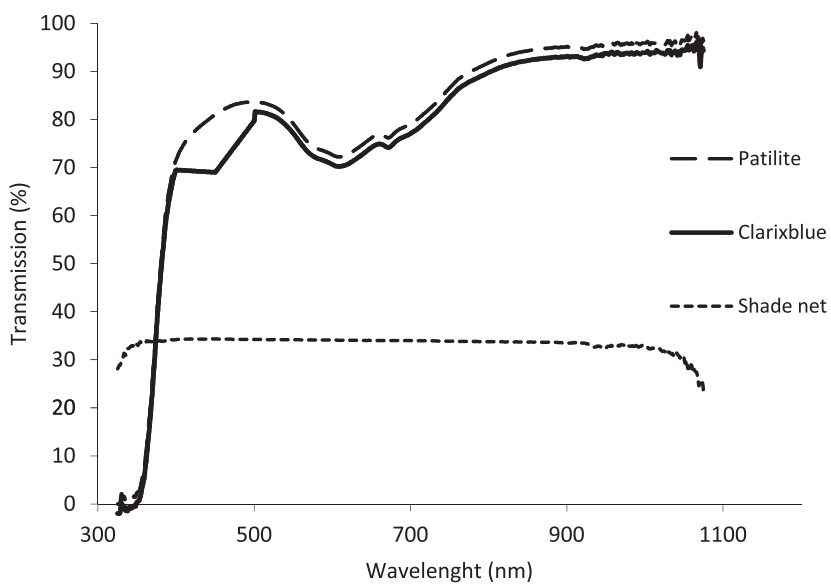

Figure 1. Spectral transmission of the plastic films (Patilite and Clarixblue) and the shade net used to cover yarrow plants grown at Bormio (Italian Alps). Data were recorded on a clear and sunny day.

Table 2. Total solar radiation, average temperature and rainfall during the 2006-2007 growing seasons. Data were recorded at Bormio and provided by Regional Agency for Environmental Protection (ARPA).

\begin{tabular}{|c|c|c|c|c|c|c|}
\hline & \multicolumn{2}{|c|}{$\begin{array}{l}\text { Total solar } \\
\text { radiation } \\
\left(\mathrm{W} \mathrm{m}^{-2}\right)\end{array}$} & \multicolumn{2}{|c|}{$\begin{array}{c}\text { Temperature } \\
\left({ }^{\circ} \mathrm{C}\right)\end{array}$} & \multicolumn{2}{|c|}{ Rainfall (mm) } \\
\hline & 2006 & 2007 & 2006 & 2007 & 2006 & 2007 \\
\hline May & 236.0 & 256.9 & 11.7 & 12.9 & 43.8 & 64.2 \\
\hline June & 288.9 & 273.9 & 16.4 & 15.9 & 46.2 & 92.2 \\
\hline July & 278.0 & 261.1 & 19.5 & 17.9 & 64.0 & 115.0 \\
\hline August & 203.4 & 207.1 & 13.9 & 16.2 & 105.8 & 111.0 \\
\hline Average & 251.5 & 249.7 & 15.4 & 15.7 & 64.9 & 95.3 \\
\hline
\end{tabular}

HPLC analysis of phenylpropanoid compounds. Phenolic compounds analysis was performed on crude methanolic extracts obtained from fresh leaves and inflorescences. Fifteen grams of leaf and inflorescence samples, derived from at least 10 pooled flowering stems, were finely chopped and, to preserve phytochemicals from oxidation and enzymatic degradation, immediately mixed with $80 \mathrm{~mL}$ of methanol and kept in the dark for $24 \mathrm{~h}$ at room temperature. These extracts were then filtered through a $0.45 \mu \mathrm{m}$ MILLEX $^{\circledR} \mathrm{HV}$ filter (Millipore, Milan, Italy) and stored at $-20^{\circ} \mathrm{C}$ until analysis.

The main phenolic constituents of yarrow's methanolic extracts were identified as hydroxycinnamic acids [5-O-caffeoylquinic acid (CGA); 3,5di- $O$-caffeoylquinic acid (3,5-diCQA) and 4,5-di-O-caffeoylquinic acid (4,5-diCQA)] by NMR and HPLC-ESI-MS as previously described by Giorgi et al. $(22,24)$. In addition, in this study, some of the phenolic compounds found in the inflorescence extracts were identified as flavonoids through liquid chromatography-mass spectrometry. The LC-MS system was constituted by a ThermoFinnigan LCQ Advantage instrument equipped with an Electrospray Ionization (ESI) source operating in the negative mode, a Surveyor LC pump and a Surveyor PDA Photodiode Array UV detector. MS operating conditions were as follows: capillary temperature, $275^{\circ} \mathrm{C}$; ionization voltage, $3.5 \mathrm{kV}$; collision energy, $35 \%$. Nitrogen was used as the sheath gas and the scan range was $\mathrm{m} / \mathrm{z}$ 50-1000. Peaks corresponding to luteolin-7-O-glucoside and apigenin-7glucoside were confirmed by comparison of their retention times, UV and MS spectra of authentic reference compounds. Separations were achieved on a reversed phase column C-18 Hypersil ODS (Supelco, particle size $5 \mu \mathrm{m}, 250 \mathrm{~mm} \times 4.6 \mathrm{~mm}$ ) with a C-18 precolumn. Gradients were generated using $0.05 \%$ formic acid in water (solvent $\mathrm{A}$ ) and methanol (solvent B) starting at $25 \% \mathrm{~B}$ at a constant flow rate of $1 \mathrm{~mL} \mathrm{~min}{ }^{-1}$. Solvent B was then increased to $70 \%$ at $24 \mathrm{~min}, 85 \%$ at $30 \mathrm{~min}, 100 \%$ at $31 \mathrm{~min}$ and finally, isocratic elution with $100 \% \mathrm{~B}$ until $34 \mathrm{~min}$.

Quantification of hydroxycinnamic acids and flavonoids was achieved by external standardization with reference compounds (Sigma-Aldrich, 
Milan, Italy). This analysis was performed with an HPLC system consisting of a Waters 515 pump connected to a Waters 2487 Dual $\lambda$ Absorbance UV Detector set at 290 and $340 \mathrm{~nm}$ (Waters, Milan, Italy) using the same gradients described above. The injection volume was $20 \mu \mathrm{L}$. Data were processed with a computer controlled system using upgraded Millenium32 software.

Antioxidant capacity assay. Antioxidant capacity of leaf and inflorescence methanolic extracts, obtained as outlined above, was determined with 2,2-diphenyl-1-picrylhydrazyl radical (DPPH') as described by Giorgi et al. (28). Results were expressed as 1/IC50.

Statistical analysis. Data were subjected to two-way analysis of variance or Pearson correlation using SigmaStat ${ }^{\circledR} 3.1$ (Systat Software Inc., San Jose, CA). When significant differences were found, means were separated using the Duncan's multiple range test at the $P<0.05$ level.

\section{RESULTS AND DISCUSSION}

\section{Plant growth and development under different light environments}

With the exception of the maximum plant height, the growing season had a strong effect on all growth parameters considered in this study (Table 3).

In the second year of cultivation, there was a consistent increase in biomass accumulation (for both fresh and dry weight) compared to 2006 (Table 4).

Table 3. Summary of results of ANOVA showing the effects of the growing season (year) and light environment on some growth parameters (Fw: fresh weight, Dw: dry weight) of yarrow plants grown at Bormio.

\begin{tabular}{llcc}
\hline & \multicolumn{3}{c}{ Source of variation } \\
\cline { 2 - 4 } Variable & Year & $\begin{array}{c}\text { Light } \\
\text { environment }\end{array}$ & $\begin{array}{c}\text { Year } \times \text { Light } \\
\text { environment }\end{array}$ \\
\hline Max plant height & NS & NS & NS \\
Stem number & $* *$ & NS & NS \\
Stem Fw & $*$ & NS & NS \\
Stem Dw & $* *$ & NS & NS \\
Leaf Fw & $* * *$ & $* *$ & NS \\
Leaf Dw & $* * *$ & NS & NS \\
Inflorescence Fw & $* * *$ & $* *$ & $*$ \\
Inflorescence Dw & $* * *$ & $*$ & NS \\
Total biomass Fw & $* * *$ & NS & NS \\
Total biomass Dw & $* * *$ & NS & NS \\
Leaf/Stem ratio Fw & $*$ & $* * *$ & \\
Leaf/Stem ratio Dw & $* * *$ & $* * *$ & \\
\end{tabular}

Significance levels are indicated by asterisks: ${ }^{*} P<0.05, * * P<0.01$, *** $P<0.001$, NS not significant.

Table 4. Effect of the growing season on some growth parameters ( $\mathrm{Fw}$ : fresh weight, Dw: dry weight) of yarrow cultivated at Bormio.

\begin{tabular}{lcc}
\hline & \multicolumn{2}{c}{ Growing season } \\
\cline { 2 - 3 } Growth parameter & 2006 & 2007 \\
\hline Stem number (per plant) & $37.3 \pm 2.0$ & $51.7 \pm 2.8$ \\
Stem Fw (g per plant) & $432.1 \pm 28.7$ & $584.8 \pm 41.6$ \\
Stem Dw (g per plant) & $168.1 \pm 11.9$ & $228.2 \pm 14.6$ \\
Leaf Fw (g per plant) & $205.1 \pm 13.9$ & $329.6 \pm 31.3$ \\
Leaf Dw (g per plant) & $24.8 \pm 1.3$ & $80.2 \pm 5.2$ \\
Inflorescence Fw (g per plant) & $47.0 \pm 6.4$ & $217.6 \pm 17.0$ \\
Inflorescence Dw (g per plant) & $15.3 \pm 2.3$ & $63.4 \pm 7.1$ \\
Total biomass Fw (g per plant) & $684.2 \pm 39.9$ & $1132.1 \pm 74.6$ \\
Total biomass Dw (g per plant) & $208.3 \pm 15.5$ & $371.9 \pm 33.5$ \\
\end{tabular}

$\overline{\text { Values are the mean } \pm \mathrm{SE}(n=12) \text { of samples collected from all light }}$ environments.
Such an effect is most likely due to the enhanced number of floral stems and/or influenced by water availability as the average rainfall greatly increased in 2007 growing season (Table 2).

Alternatively, this general biomass enhancement from 2006 to 2007 may be the results of the natural ontogenic cycle of yarrow plants.

The effect of light environment on yarrow growth parameters was not as widespread as it was for the growing season. However, leaf and inflorescence fresh weight, and the leaf/stem ratio (for both fresh and dry weight) were significantly influenced by light environment (Table 3).

The effect of light conditions on leaf and inflorescence dry weight was very similar to that observed for fresh weight (data not shown).

Yarrow plants grown under the shade net displayed a greater leaf development, a parallel decrease in inflorescence formation and a remarkable increase in the leaf/stem ratio compared to others light conditions (Table 5).

A reduction in inflorescence development was also observed under the Clarixblue film compared to full sun growing plants. Total plant fresh weight was unaffected by light treatments (Table 3). Analysis of variance showed that there was an interactive effect of the growing season and the light environments on inflorescences dry weight (Table 3).

In fact, whereas inflorescence dry weight was very similar for all the light treatments in 2006, during the second growing season yarrow plants cultivated under Clarixblue, Patilite and the shade net displayed a lower inflorescences formation than those exposed to full sun (data not shown). This indicates that at least for inflorescences development an adaptation to the light environment during the two growing seasons occurred, which demonstrate the importance of long-term studies of this topic on perennial plants.

One of the most interesting finding of this study is the switch in carbon allocation between leaves and inflorescences due to severe PAR decrease by shade net (Table 1) which, however, did not alter the total plant fresh and dry biomass (Table 3).

In radish plants, carbon partitioning between roots and the epigeous apparatus was altered by different light quality (29). The change in leaf/stem ratio suggests that yarrow plants have probably responded to limited light availability by increasing the number and/or the expansion of leaf tissues as observed in Phillyrea latifolia (6). The greater leaf development observed here might also be attributable to decreased photosynthetic capacity in yarrow leaves induced by long-term shading conditions (30).

It is quite surprising that plant height was unchanged under shade condition (Table 3 ). In fact, it is well known that a

Table 5. Effect of light environment on fresh weight of leaves, inflorescences, total plant biomass and leaf/stem ratio of plants grown at Bormio.

\begin{tabular}{lccrc}
\hline $\begin{array}{l}\text { Light } \\
\text { environment }\end{array}$ & $\begin{array}{c}\text { Leaves } \\
\text { (g per plant) }\end{array}$ & $\begin{array}{c}\text { Inflorescences } \\
\text { (g per plant) }\end{array}$ & $\begin{array}{c}\text { Total plant } \\
\text { (g per plant) }\end{array}$ & $\begin{array}{c}\text { Leaf/stem } \\
\text { ratio }\end{array}$ \\
\hline Full sun & $217.7 \pm 22.5^{\mathrm{b}}$ & $166.1 \pm 50.7^{\mathrm{a}}$ & $870.8 \pm 100.0$ & $0.4 \pm 0.0^{\mathrm{b}}$ \\
Shaded & $357.4 \pm 56.3^{\mathrm{a}}$ & $105.1 \pm 37.0^{\mathrm{b}}$ & $1000.9 \pm 162.0$ & $0.6 \pm 0.0^{\mathrm{a}}$ \\
Clarixblue & $245.7 \pm 31.5^{\mathrm{b}}$ & $111.9 \pm 33.5^{\mathrm{b}}$ & $862.6 \pm 111.6$ & $0.4 \pm 0.0^{\mathrm{b}}$ \\
Patilite & $248.7 \pm 36.2^{\mathrm{b}}$ & $146.1 \pm 41.3^{\mathrm{ab}}$ & $898.5 \pm 143.2$ & $0.5 \pm 0.0^{\mathrm{b}}$
\end{tabular}

Each data is the mean \pm SE $(n=6)$ of samples harvested in 2006 and 2007. For each column, different letters indicate significant differences at the $P<0.05$ level according to the Duncan test. Column with no letter are not significantly different. 
common response of plants to shade is the stimulation of shoot elongation, which is triggered by the low-red/far-red ratio. Based on the fact that plant height remained constant also in both growing season, we suggest that this growth parameter is an inherent trait of the cultivar "SPAK". Shade-inducing elongation is often associated with a reduction in leaf development and a decrease in branching (31). In yarrow plants, we did not observe any of these shade-avoidance responses and we hypothesize that this might be related is a shade-tolerant species.

As showed in several studies $(2,14,18,32)$, a decrease in plant biomass is expected under increasing UV radiation, due to the reduction in photosynthetic capacity, leaf biomass or photosynthetic area or to the redirection of carbon skeleton to the biosynthesis of UV-protecting compounds.

Table 6. Summary of results of ANOVA showing the effects of the growing season (year) and light environment on leaf and inflorescence contents of caffeic acid derivatives and flavonoids in yarrow plants grown at Bormio.

\begin{tabular}{lllcc}
\hline & & \multicolumn{3}{c}{ Source of variation } \\
\cline { 3 - 5 } Organ & Variable & Year & $\begin{array}{c}\text { Light } \\
\text { environment }\end{array}$ & $\begin{array}{c}\text { Year } \times \\
\text { Light } \\
\text { environment }\end{array}$ \\
\hline Leaves & CGA & $* * *$ & NS & NS \\
& 3,5-diCQA & $* * *$ & $* * *$ & NS \\
& 4,5-diCQA & $* *$ & $* *$ & NS \\
& Total caffeic & $* * *$ & $*$ & NS \\
Inflorescences & acid der. & & & \\
& CGA & NS & $*$ & NS \\
& 3,5-diCQA & NS & $*$ & NS \\
& 4,5-diCQA & NS & $* *$ & NS \\
& Total caffeic & NS & $*$ & NS \\
& acid der. & & & \\
& Lut-7- $O$-gluc & NS & $*$ & NS \\
Apig-7- $O$-gluc & NS & $*$ & NS \\
& Total flavonoids & NS & $*$ & NS \\
& Lut/Apig ratio & NS & $*$ & NS
\end{tabular}

$\overline{\text { CGA, chlorogenic acid; diCQA, dicaffeoylquinic acid; lut, luteolin; apig, }}$ apigenin; gluc, glucoside. Significance level is indicated by asterisks: $* P<0.05,{ }^{*} P<0.01,{ }^{* * *} P<0.001$, NS not significant.
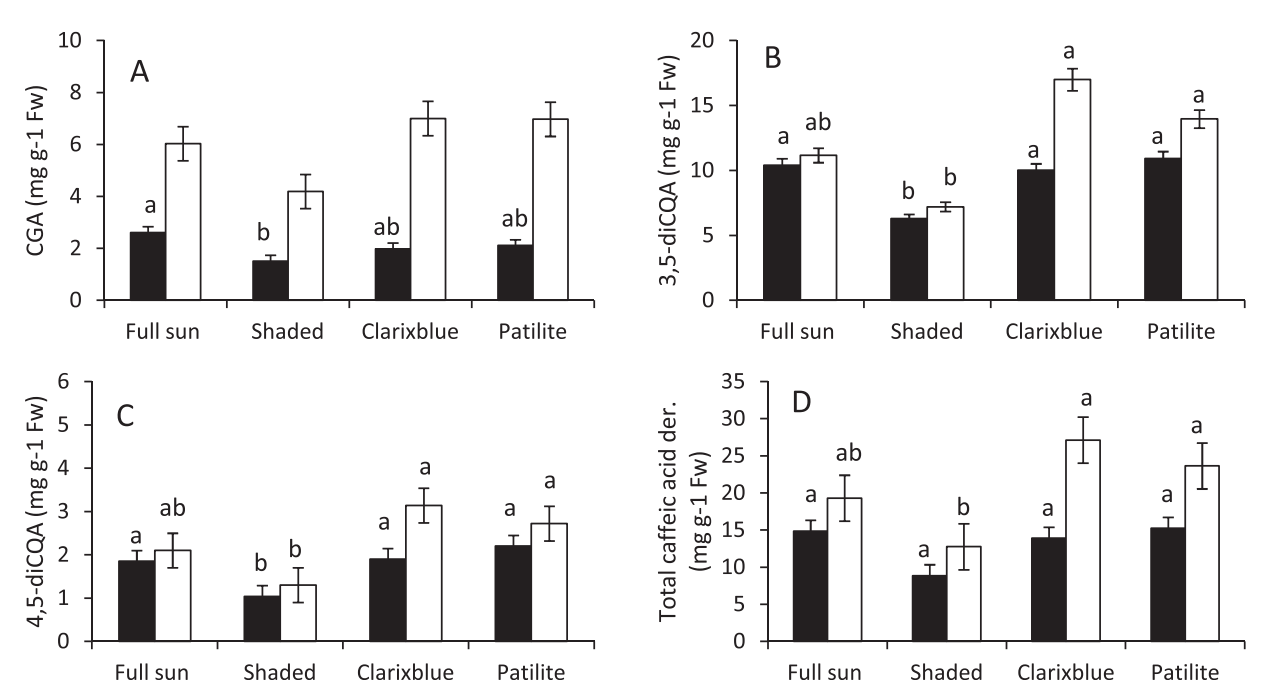

Figure 2. Effect of light environment over two growing seasons (2006: black bars; 2007: white bars) on the content of CGA (A), 3,5-diCQA (B), 4,5diCQA (C) and total caffeic acid derivatives (D) in leaves of yarrow plants grown at Bormio. Each bar is the mean of samples collected in 2006 and $2007 \pm$ standard deviation $(n=6)$. Within each plot, different letters indicate significant differences at the $P<0.05$ level according to the Duncan test. Bars without letters are not significantly different.
Tsormpatsidis et al. (17) reported an increase in total above ground biomass and leaf number of lettuce plants grown under plastic films with progressive UV wavebands cutoff. For yarrow instead, the reduction in UV transmission by about $90 \%$ under growth in comparison with full sun.

\section{Caffeic acid derivatives in leaves and inflorescences}

Two-way analysis of variance showed that the content of selected phenylpropanoids in yarrow was differently influenced by the growing season and light treatments depending on the organ (leaves or inflorescences; Table 6).

In fact, phenylpropanoids contents in leaves were significantly affected by the growing season, whereas in inflorescences their levels remained constant in 2006-2007. Interactive effects of the year of cultivation and light treatments on the content of these compounds were never found (Table 6).

Regardless of light treatment, CGA, 3,5-diCQA, 4,5-diCQA and total caffeic acid derivatives in leaves increased by $64 \%$, $107 \%, 125 \%$ and $97 \%$, respectively, in 2007 compared to 2006 . Leaf tissues had overall higher levels of caffeic acid derivatives than inflorescences (Figs. 2 and 3). In particular, the leaf CGA level was two to three times higher compared to that of the inflorescences. The highest accumulation of dicaffeoylquinic acids (3,5 and 4,5-diCQA) and total caffeic acid derivatives was observed in leaves of plants cultivated under Clarixblue and Patilite films (Fig. 2B,C,D).

The inflorescences of full sun-grown plants showed the highest level of CGA, whereas its content was reduced by about $23 \%$ or $42 \%$ by both Clarixblue and Patilite films and by the shade net, respectively (Fig. 3). Although CGA accumulation in leaf tissues (Fig. 2A) was similar to that observed in inflorescences, its level was not significantly affected by the light treatments (Table 6). The content of dicaffeoylquinic acids and total caffeic acid derivatives in the inflorescences was very similar in plants raised in full sun, Clarixblue and Patilite films, whereas a strong reduction in their biosynthesis and accumulation occurred under the shade net (Fig. 3). Clarixblue and Patilite films (Table 1) did not improve plant 


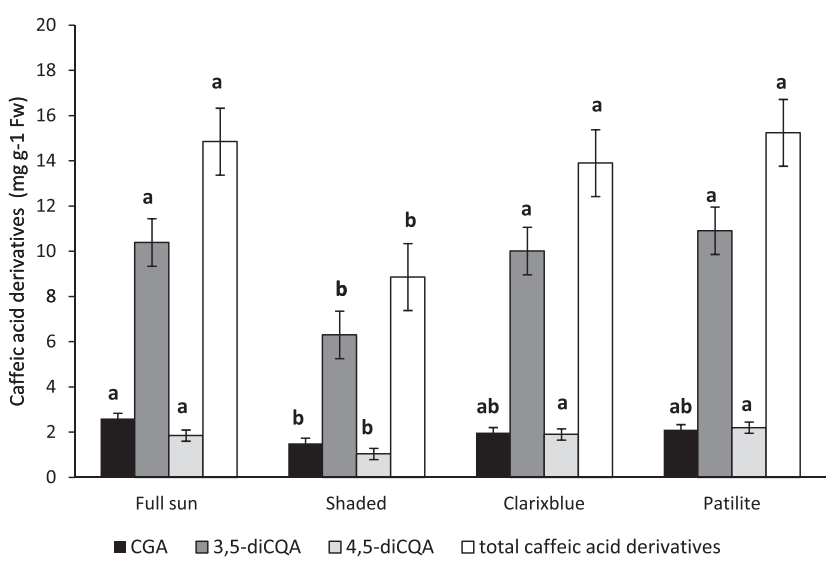

Figure 3. Effect of the light environment on the content of CGA, 3,5diCQA, 4,5-diCQA and total caffeic acid derivatives in inflorescences of yarrow plants grown at Bormio. Each bar is the mean of samples collected in 2006 and $2007 \pm$ standard deviation $(n=6)$. For each compound, different letters indicate significant differences at the $P<0.05$ level according to the Duncan test.

It is known that the concentrations of phenylpropanoids may change throughout the plant ontogenic development according to plant species or to specific phenylpropanoids class or compound (33). For instance, the reductions in the concentration of caffeoylquinic acids and epicuticular flavonoids have been reported in older leaves of coffee and birch plants, respectively $(34,35)$. In field-grown silver birch, Tegelberg et al. (7) found an increased content of neochlorogenic acid and 3,4-dihydroxypropiphenone-3-glucoside in older silver birch plants while CGA and coumarylic acids were unchanged within different growing seasons. Although a negative correlation is generally expected between growth and content of secondary metabolites, we observed in yarrow the parallel enhancement of leaf phenylpropanoids along with that of leaf fresh biomass. Our results are in agreement with Riipi et al. (33), and this may be explained by the fact that hydroxycinnamates also display important structural roles in plants and they may increase in parallel with enhanced plant growth. Interestingly, the content of caffeic acid derivatives in yarrow inflorescences did not change in the two growing season.

Similar findings have been reported in flowering heads of Arnica montana cv. ARBO grown in the Alps (36). One of the reasons of such phytochemical stability through growing seasons in yarrow inflorescences could be addressed by the use of a genetically homogenous population (e.g. cultivar) that has been selected for its high constitutive level of secondary metabolites. Furthermore, as suggested by Zidorn and Stuppner (37), it seems that for several species of the Asteraceae family, the use of flowering tops in quantitative phytochemical studies is suitable because they are less affected by seasonal variation.

It is hypothesized that such physiological and biochemical change and intensive biosynthesis of certain bioactive compounds, such as caffeic acid derivatives, are an essential part of plant adaptation to environmental stress, as high solar radiation (20). In this study, the light environment influenced the accumulation of caffeic acid derivatives in yarrow plants mostly in inflorescences, but in agreement with Tattini et al. (6), not their composition. Similar findings have been reported in the case of lemon balm (Melissa officinalis L.) and sage (Salvia officinalis L) (20).
In a field study on Mahonia repens, the content of CGA was markedly lower in deeply shaded leaves than in partially and fully exposed leaves suggesting that a threshold of light exposure would be enough to trigger CGA accumulation (8). In flowering head of A. montana, the amount of dicaffeoylquinic acid correlated well with the altitude and consequently with increased UV-B exposition (9).

Based on our results, it is unlikely that UV radiation has a strong impact on the biosynthesis of phenylpropanoids in yarrow leaves as the concentration of these compounds under Patilite and Clarixblue films, which cut off more than $90 \%$ of UV wavebands (Table 1), was as high as that found in full sun growing plants.

Plants grown under the shade net, reducing also UV transmission, display a slightly reduced concentration of caffeic acid derivatives compared with full sun plants. Therefore, it appears that yarrow leaves have a rather high constitutively level of caffeic acid derivatives which are, at least in our experimental conditions, poorly affected by light environments. On the other hand, the higher level of CGA in inflorescences of full sun plants compared with those raised under Patilite and Clarixblue films and the shade net, suggest that, in this organ, this compound is synthesized in response to high solar radiation and that it may confer enhanced tolerance to oxidative stress (3). Furthermore, the highest level of diCQAs and total amount of caffeic acid derivatives detected in leaf tissues of plants grown under Clarixblue and Patilite may be caused by high temperature stress as these films retained much of the infrared radiation (Table 1).

Finally, it should be pointed out that, besides UV radiation, the cladding materials used in this study cut off relevant amounts
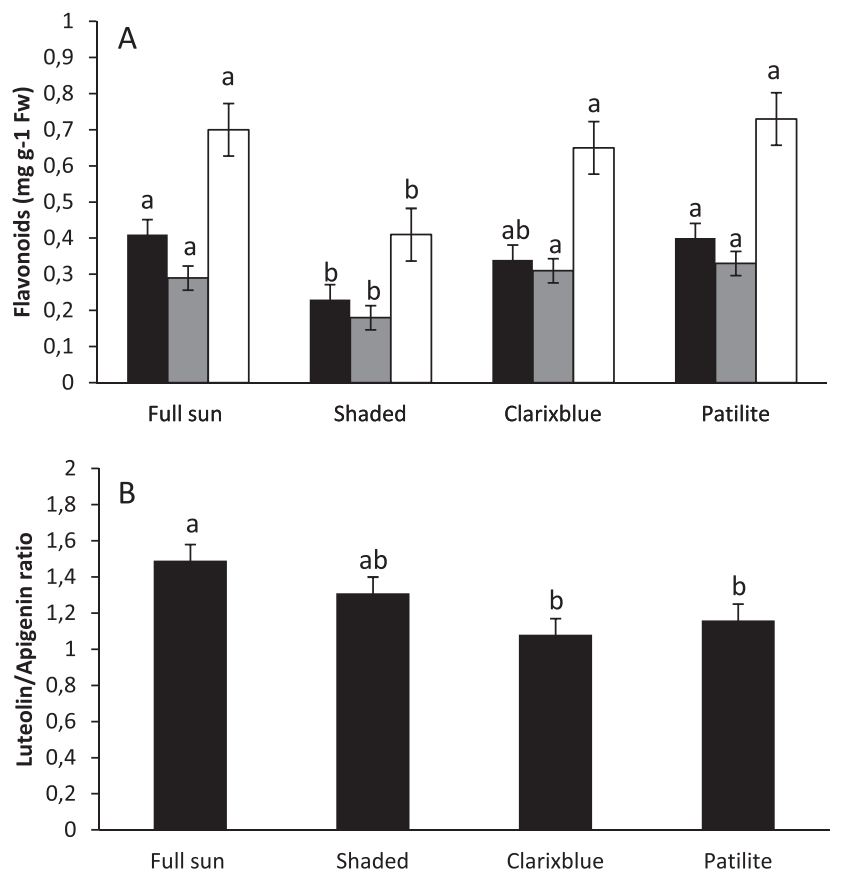

Figure 4. Effect of light environment on the content of luteolin-7-Oglucoside, (A, black bars), apigenin-7-O-glucoside (A, gray bars), total flavonoids (A, white bars) and luteolin to apigenin ratio (B) in inflorescences of yarrow grown at Bormio. Each bar is the mean of samples collected in 2006 and $2007 \pm$ standard deviation $(n=6)$. Within each plot and individual compound (A), different letters indicate significant differences at the $P<0.05$ level according to the Duncan test. 
of the PAR which account for about $20 \%$ and $70 \%$ (Table 1, Fig. 1) for the two plastic films and the shade net, respectively. Therefore, it seems that the overall reduction in phenylpropanoid content in shade plants is due to the preferential allocation of resource to leaf growth, as shown by fresh and dry weight variations.

\section{Flavonoids in yarrow inflorescences}

Besides caffeic acid derivatives, we identify in inflorescences methanolic extracts, through LC-MS analysis, two flavonoid compounds as luteolin-7-O-glucoside and apigenin-7- $O$-glucoside. Positive ion electrospray (ESI) MS/MS spectra of these flavonoids were in agreement with those described by Atoui et al. MS spectrum of these flavonoids gave a $[\mathrm{M}+\mathrm{H}]^{+}$ion at $\mathrm{m} / \mathrm{z} 577$ and 433, and a fragment at $\mathrm{m} / \mathrm{z} 287$ and 271 for luteolin-7-O-glucoside and apigenin-7- $O$-glucoside, respectively (38).
These compounds are, among the flavonoid blend of A. collina inflorescences, the most abundant as reported earlier by Benedek et al. (23). Flavonoids content in yarrow inflorescences was appreciably lower than that of caffeic acid derivatives (Fig. 4). Luteolin-7- $O$-glucoside, apigenin-7- $O$-glucoside and total flavonoid levels were significantly reduced in shaded plants, whereas Clarixblue and Patilite did not affect their content compared with full sun growing plants (Fig. 4A). Luteolin to apigenin ratio decreased significantly in yarrow inflorescences developed under the different cladding materials, especially beneath Clarixblue and Patilite films (Fig. 4B).

Enhancement of flavonoids content in various plant tissues, especially of those glycosilated, following exposition to excess solar radiation or UV-B is a well documented phenomenon (5, $6,8)$. However, there are some reports in which the contents of individual or total flavonoids do not correlate with increasing level of solar radiation and UV-B $(9,36)$. Rather than affecting

$\diamond \mathrm{CGA} \square$ diCQAs $\triangle$ total caffeic acid derivatives

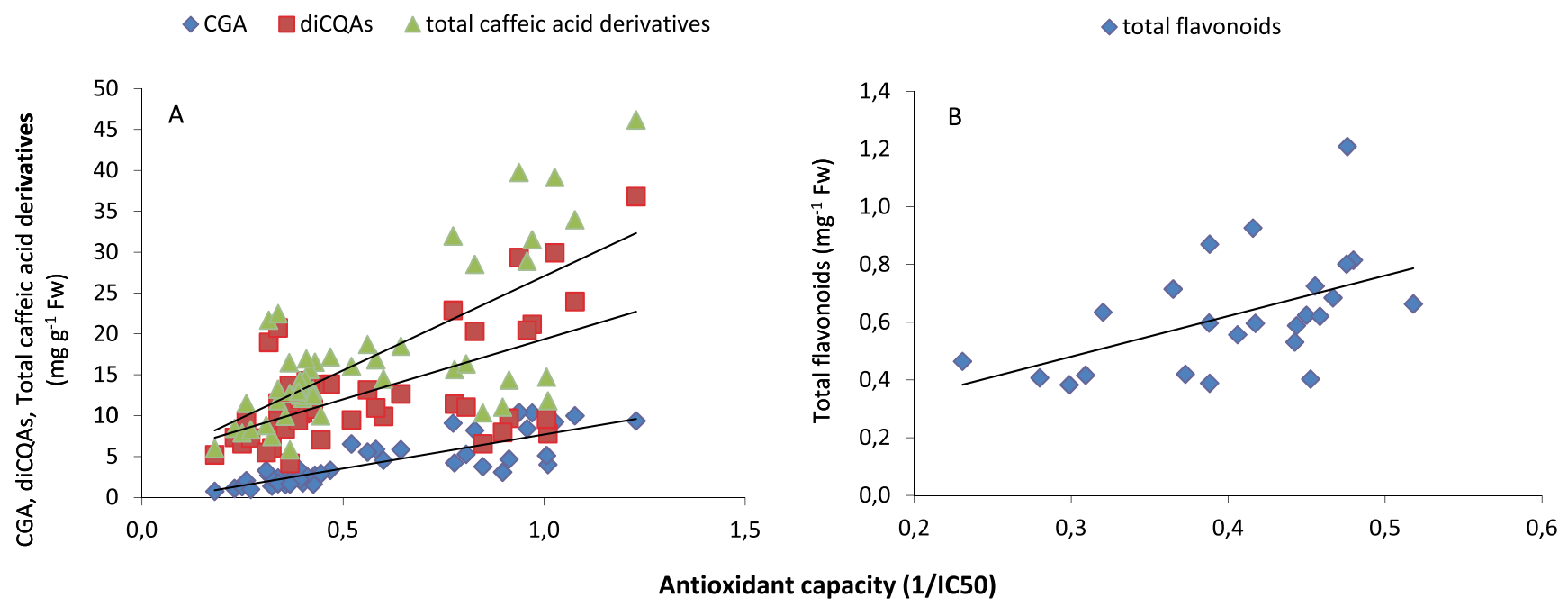

Figure 5. Pearson correlation of the antioxidant capacity (1/IC50) of the methanolic extracts and the content (mg g ${ }^{-1}$ Fw) of CGA (A), diCQAs (A), total caffeic acid derivates (A) of yarrow leaves and inflorescences and the concentration of total flavonoids in inflorescences (B). Each dot represents a single analyzed sample.
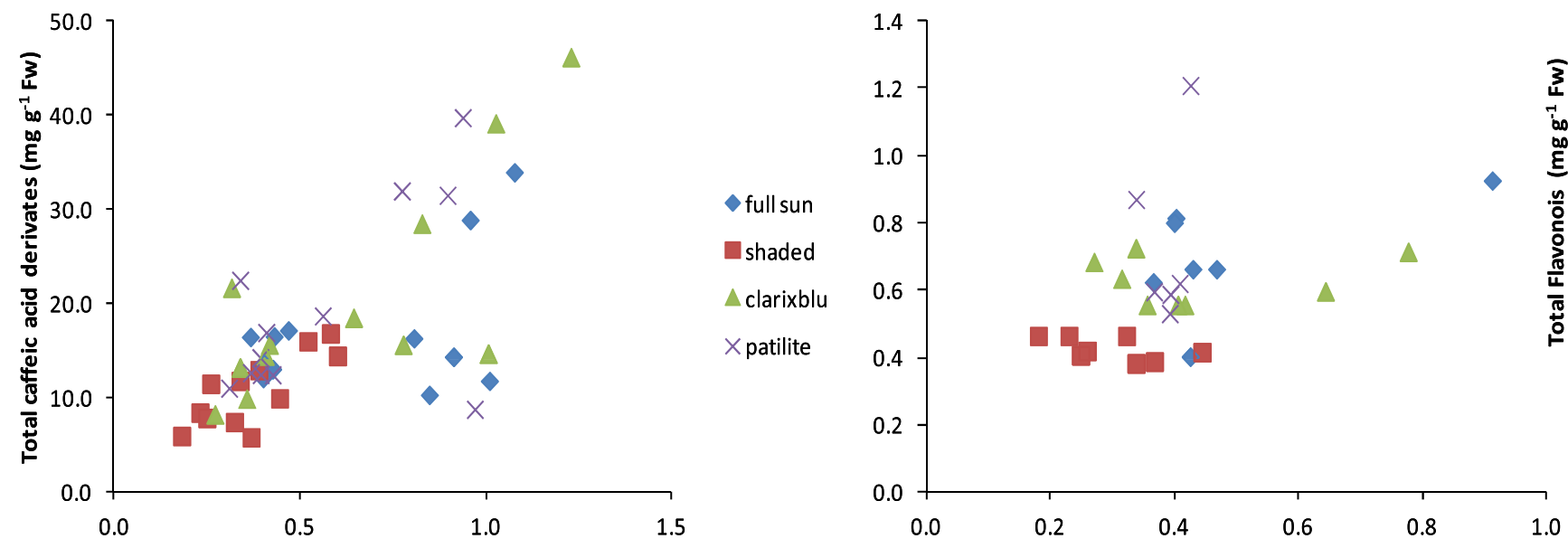

Antioxidant capacity (1//C50)

Figure 6. Pearson correlation of the antioxidant capacity (1/IC50) of the methanolic extracts and the content (mg g $\left.{ }^{-1} \mathrm{Fw}\right)$ of total caffeic acid derivates of yarrow leaves and inflorescences and the concentration of total flavonoids in inflorescences under different light environments (full sun, polyethylene films and shade net). Each dot represents a single analyzed sample. 
the absolute content of flavonoids, there is increasing evidence that excess light induce the preferential accumulation of orthodihydroxilated B-ring flavonoids over their monohydroxilated counterpart (10).

This occurs because orthodihydroxilated flavonoids may efficiently dissipate excess energy and scavenge reactive oxygen species $(12,39)$. It is concluded that preferential accumulation of orthodihydroxilated flavonoids participate, along with CGA, in the response mechanism to high light irradiance.

\section{Antioxidant capacity of methanolic extracts and their relation to phenylpropanoids content}

Considering both inflorescences and leaves, the Pearson correlation analysis (Fig. 5) showed a positive and significant relationship among the antioxidant capacity, as measured by the DPPH assay, and the content of total caffeic acid derivatives $(y=$ 23.047x $+4.0123, r=0.69, P<0.001)$, CGA $(y=8.3153 x-$ $0.6168, r=0.82, P<0.001)$ and diCQAs $(y=14.732 x+4.6291$, $r=0.59, P<0.001)$. These results are in agreement with our previous finding $(22,28)$, and support the concept that, among caffeic acid derivatives, CGA-more than the diCQAs - is a powerful free radical scavenger. Conversely, correlation between the antioxidant capacity and total flavonoid content display a rather weak though significant relation $(y=1.4055 x+0.1295, \quad r=0.51$, $P<0.05$, Fig. 3B). Finally, the correlation of the antioxidant capacity (1/IC50) of the methanolic extracts and the content $\left(\mathrm{mg} \mathrm{g}^{-1} \mathrm{Fw}\right)$ of total caffeic acid derivates as well as of total flavonoids under different light environments (full sun, polyethylene films and shade net) was evaluated (Fig. 6). No significant impact of the different light environments tested on antioxidant capacity of the extracts was shown.

\section{CONCLUSION}

Our results show that the growing season and the light environment considerably affect growth and phenylpropanoid accumulation in yarrow plants. Phenylpropanoid levels in inflorescences appear to be more sensitive to the light environment than leaves as the latter showed high constitutive amounts of these compounds. However, the use of polyethylene films improved to some extent the content of caffeic acid derivatives in leaves suggesting that they may be used as a way to enhance these important bioactive compounds and thus the value of herbal products.

Acknowledgements-This study was partly supported by a grant from "Accordo di Programma, affermazione in Edolo del Centro di Eccellenza Università della Montagna" MIUR-Università degli Studi di Milano, prot. no. 386 1293-05/08/2011

\section{REFERENCES}

1. Sharma, P., A. B. Jha, R. S. Dubey and M. Pessarakli (2012) Reactive oxygen species, oxidative damage, and antioxidative defense mechanism in plants under stressful conditions. J. Bot., 2012, Article ID 217037.

2. Dixon, R. A. and N. L. Paiva (1995) Stress-induced phenylpropanoid metabolism. Plant Cell. 7, 1085-1097.

3. Grace, S. C. and B. A. Logan (2000) Energy dissipation and radical scavenging by the plant phenylpropanoid pathway. Phil. Trans. $R$ Soc. Lond. B. 355, 1499-1510.
4. Klem, K., A. Ač, P. Holub, D. Kováč, V. Špunda, M. Robson and O. Urban (2012) Interactive effects of PAR and UV radiation on the physiology, morphology and leaf optical properties of two barley varieties. Environ. Exp. Bot. 75, 52-64.

5. Agati, G., E. Azzarello, S. Pollastri and M. Tattini (2012) Flavonoids as antioxidants in plants: Location and functional significance. Plant Sci. 196, 67-76.

6. Tattini, M., E. Gravano, P. Pinelli, N. Mulinacci and A. Romani (2000) Flavonoids accumulate in leaves and glandular trichomes of Phyllirea latifolia exposed to excess solar radiation. New Phytol. 148, 69-77.

7. Tegelberg, R., R. Julkunen-Tiitto and P. J. Aphalo (2001) The effects of long-term elevated UV-B on the growth and phenolics of field-grown silver birch (Betula pendula). Global Change Biol. 7, 839-848.

8. Grace, S. C., B. A. Logan and W. W. III Adams (1998) Seasonal differences in foliar content of chlorogenic acid, a phenylpropanoid antioxidant, in Mahonia repens. Plant, Cell Environ. 21, 513-521.

9. Spitaler, R., P. D. Schlorhaufer, E. P. Ellmerer, I. Merfort, S. Bortenschlager, H. Stuppner and C. Zidorn (2006) Altitudinal variation of secondary metabolite profile in flowering heads of Arnica montana CV. ARBO. Phytochem. 67, 409-417.

10. Markham, K. R., K. G. Ryan, S. J. Bloor and K. A. Mitchell (1998) An increase in the luteolin: Apigenin ratio in Marchantia polymorpha on UV-B enhancement. Phytochemistry 48, 791-794.

11. Tattini, M., L. Guidi, L. Morassi-Bonzi, P. Pinelli, D. Remorini, L. Degl'Innocenti, C. Giordano, R. Massai and G. Agati (2005) On the role of flavonoids in the integrated mechanisms of response of Ligustrum vulgare and Phyllirea latifolia to high solar radiation. New Phytol. 167, 457-470.

12. Rice-Evans, C. A., N. J. Miller and G. Paganga (1999) Antioxidant properties of phenolic compounds. Trends Plant Sci. 2, 152-159.

13. Landry, L. G., C. C. S. Chapple and R. L. Last (1995) Arabidopsis mutants lacking phenolic sunscreens exhibit enhanced ultraviolet-B injury and oxidative damage. Plant Physiol. 109, 1159-1166.

14. Kriziek, D. T. (2004) Influence of PAR and UV-A in determining plant sensitivity and photomorphogenic responses to UV-B radiation. Photochem. Photobiol. 79, 307-315.

15. Fletcher, J. M., A. Tatsiopoulou, M. Mpezamihigo, J. G. Carew, R. G. C. Henbest and P. Hadley (2005) Far-red light filtering by plastic film, greenhouse-cladding materials: Effects on growth and flowering in Petunia and Impatiens. J. Hort. Sci. Biotechnol. 80, 303-306.

16. Lamnatou, C. and D. Chemisana (2013) Solar radiation manipulations and their role in greenhouse claddings: Fresnel lenses, NIRand UV-blocking materials. Renew. Sust. Energ. Rev. 18, 271-287.

17. Tsormpatsidis, E., R. G. C. Henbest, F. J. Davis, N. H. Battey, P. Hadley and A. Wagstaff (2008) UV irradiance as a major influence on growth, development and secondary products of commercial importance in Lollo Rosso lettuce 'Revolution' grown under polyethylene films. Environ. Exp. Bot. 63, 232-239.

18. Barnes, P. W., S. D. Flint and M. M. Caldwell (1990) Morphological responses of crop and weed species of different growth forms to ultraviolet-B radiation. Am. J. Bot. 77, 1354-1360.

19. Hermes, D. A. and W. J. Mattson (1992) The dilemma of plants: To grow or defend. Q. Rev. Biol. 67, 283-335.

20. Manukyan, A. (2013) Effects of PAR and UV-B radiation on Herbal yeld, bioactive compounds and their antioxidant capacity of some medicinal plants under controlled environmental conditions. Photochem. Photobiol. 89, 406-414.

21. Giorgi, A., M. Bononi, F. Tateo and M. Cocucci (2005) Yarrow (Achillea millefolium L.) growth at different altitudes in central Italian Alps: Biomass yield, oil content and quality. J Herbs Spices Med Plants. 11, 47-58.

22. Giorgi, A., M. Madeo, G. Speranza and M. Cocucci (2010) Influence of environmental factors on composition of phenolic antioxidants of Achillea collina Becker ex Rchb. Nat. Prod. Res. 24, 1546-1559.

23. Benedek, B., N. Gjoncaj, J. Saukel and B. Kopp (2007) Distribution of phenolic compounds in middle European taxa of the Achillea millefolium L. aggregate. Chem. Biodivers. 4, 849-857.

24. Giorgi, A., M. Mingozzi, M. Madeo, G. Speranza and M. Cocucci (2009) Effect of nitrogen starvation on the phenolic metabolism and antioxidant properties of yarrow (Achillea collina Becker ex Rchb.). Food Chem. 114, 204-211. 
25. Ai, G., Q. Liu, W. Hua, Z. Huang and D. Wang (2013) Hepatoprotective evaluation of the total flavonoids extracted from flowers of Abelmoschus manihot (L.) Medic: In vitro and in vivo studies. J. Ethnopharmacol. 146, 794-802.

26. Bravo, L., L. Goya and E. Lecumberri (2007) LC/MS characterization of phenolic constituents of mate (Ilex paraguariensis, St. Hil.) and its antioxidant activity compared to commonly consumed beverages. Food Res. Int. 40, 393-405.

27. Singh, P. P., S. Jha and R. Irchhaiya (2012) Antidiabetic and antioxidant activity of hydroxycinnamic acids from Calamintha Officinalis Moench. Med. Chem. Res. 21, 1717-1721.

28. Giorgi, A., R. Bombelli, A. Luini, G. Speranza, M. Cosentino, S. Lecchini and M. Cocucci (2009) Antioxidant and cytoprotective properties of infusions from leaves and inflorescences of Achillea collina Becker ex Rchb. Phytother. Res. 23, 540-545.

29. Keiller, D. and H. Smith (1989) Control of carbon partitioning by light quality mediated by phytochrome. Plant Sci. 63, 25-29.

30. Evans, J. R. and H. Poorter (2001) Photosynthetic acclimation of plants to growth irradiance: The relative importance of specific leaf area and nitrogen partitioning in maximizing carbon gain. Plant, Cell Environ. 24, 755-767.

31. Morelli, G. and I. Ruberti (2002) Light and shade in the photocontrol of Arabidopsis growth. Trends Plant Sci. 7, 399-404.

32. Laakso, K., J. H. Sullivan and S. Huttunen (2000) The effects of UV-B radiation on epidermal anatomy in loblolly pine (Pinus taeda
L.) and Scots pine (Pinus sylvestris L.). Plant, Cell Environ. 23, $461-472$.

33. Riipi, M., V. Ossipov, K. E. Lempa, J. Koricheva, S. Ossipova and K. Pihlaja (2002) Seasonal changes in birch leaf chemistry: Are there trade-offs between leaf growth and accumulation of phenolics? Oecologia 130, 380-390.

34. Mondolot, L., P. La Fisca, B. Buatois, E. Talansier, A. De Kochko and C. Campa (2006) Evolution in caffeoylquinic acid content and histolocalization during Coffea canephora leaf development. Ann. Bot. 98, 33-40.

35. Valkama, E., J. P. Salminen, J. Koricheva and K. Pihlaja (2004) Changes in leaf trichomes and epicuticular flavonoids during leaf development in three birch taxa. Ann. Bot. 94, 233-242.

36. Spitaler, R., A. Winkler, I. Lins, S. Yanar, H. Stuppner and C. Zidorn (2008) Altitudinal variation of phenolic contents in flowering heads of Arnica montana CV. ARBO: A 3-year comparison. J. Chem. Ecol. 34, 369-375.

37. Zidorn, C. and H. Stuppner (2001) Evaluation of chemosystematic characters in the genus Leontodon. Taxon 50, 115-134.

38. Atoui, A. K., A. Mansouri, G. Boskou and P. Kefalas (2005) Tea and herbal infusions: Their antioxidant and phenolic profile. Food Chem. 89, 27-36.

39. Smith, G. J. and K. R. Markham (1998) Tautomerism of flavonol glucosides: Relevance to plant UV protection and flower colour. J. Photochem. Photobiol. A-Chem. 118, 99-100. 